\title{
A Literature Review of Self Adjusting File
}

\author{
Özkan ADI GÜZEL
}

Assistant Professor, Dicle University, Faculty of Dentistry, Department of Operative Dentistry and Endodontics, Diyarbakır, TURKEY

\section{Key Words}

Self-adjusting file, new rotary file, nickel-titanium, endodontic files

\author{
Correspondence: \\ Özkan ADIGÜZEL \\ Dicle University, \\ Faculty of Dentistry, \\ Department of Operative Dentistry \\ and Endodontics, \\ 21280, Diyarbakir, TURKEY. \\ e-mail: \\ ozkanadiguzel@dicle.edu.tr
}

\begin{abstract}
A primary aim of root canal treatment is to completely clean and shape the root canal system. Various instruments are available for endodontic instruemntation. Although rotary systems do prepare many canals without major procedural errors, they do not address canal types with long-oval or flat cross sections. A newly developed self-adjusting file (SAF) was designed to address the shortcomings of traditional rotary files by adjusting itself to the canal cross section. This instrument consists of a compressible opened NiTi tube that, on placement into a root canal, will exert pressure against the canal Wall. The SAF is used in an in-and-out motion powered by a handpiece and under constant irrigation.
\end{abstract}

The aim of this review was to describe instrument design, usage parameters and features of Self Adjusting File.

(Int Dent Res 2011;1:18-25)

\section{I ntroduction}

The cleaning and shaping of the root canal system is an important objective of root canal treatment $(1,2)$. Original root canal path should be maintained and the root canal wall dentin should be cut circumferentially so that prepared root canal wall outline reflects the original outline (1). The goal of instrumentation is to provide a continuously tapered preparation that maintains original root canal anatomy, keeping the foramen without any ledge and transportation from the original canal curvature $(3,4)$.

A variety of instruments are available for the root canal instrumentation. For many years, hand files are the most commonly used for endodontic instruments (5). Traditionally, this group of instruments has been manufactured from stainless steel and comprises two basic designs, the K-type instruments (K-files and K-reamers) and the Hedstrom file $(5,6)$. Although almost all these instruments were designed between many years ago, important changes have introduced in recent years with regard to their quality, efficacy, and standardization (7). Nickel-titanium instruments for manuel and rotary use have been developed during the last decade (8). It was introduced to facilitate root canal instrumentation (8).

\section{Nickel-Titanium Rotary I nstruments}

Since the early 1990s, several endodontic instrument systems manufactured from nickeltitanium have been introduced into endodontic clinic practice. The specific design characteristics vary, such as tip sizing, taper, cross section, helix angle, and pitch. To date, several devices and methods have been used to perform endodontic treatment. The specific design characteristics vary, such as tip sizing, taper, helix angle, cross section (Fig. 1) (9), and pitch. New designs continually are produced (9). 

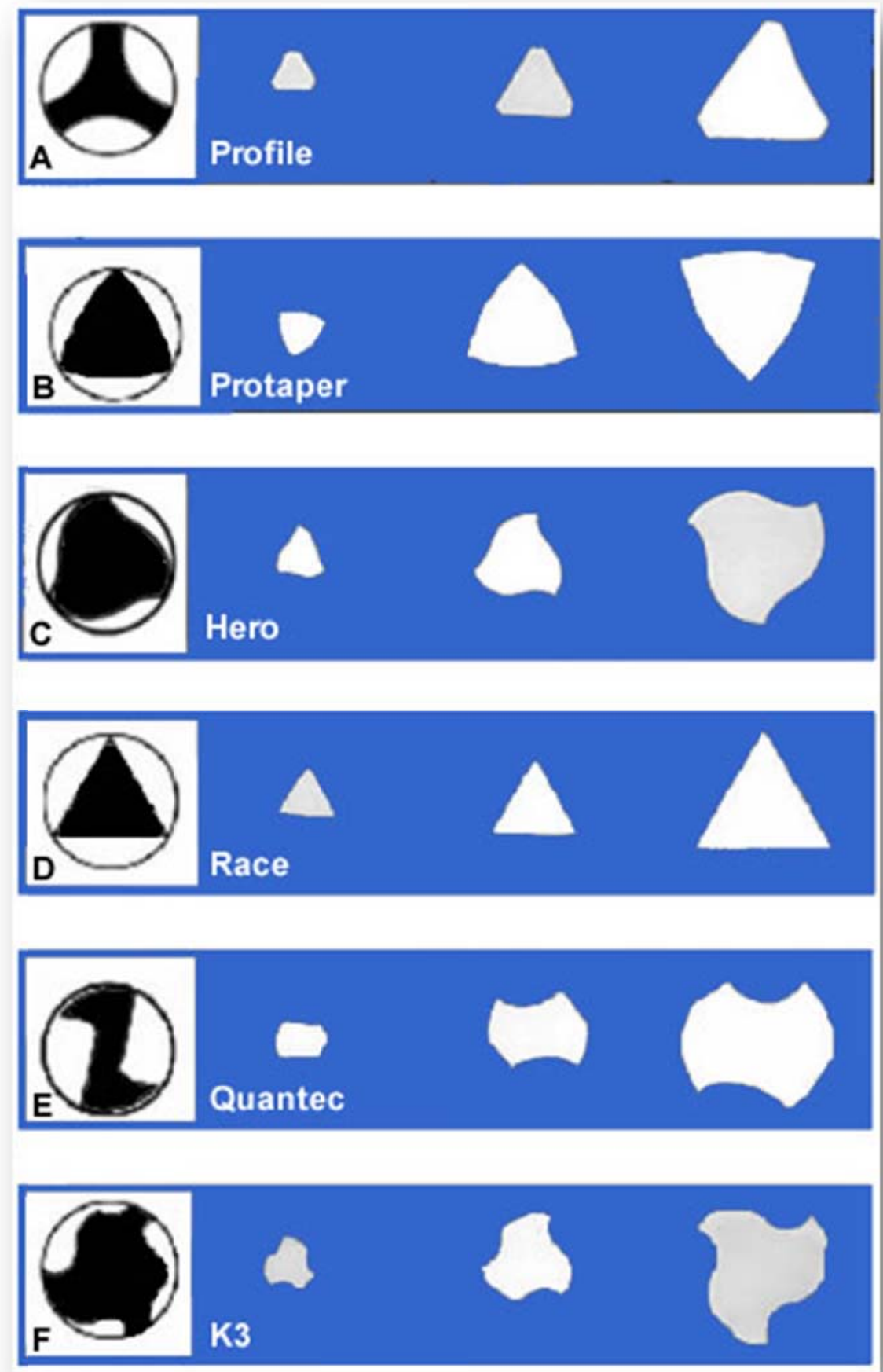

Figure 1. Cross-section designs of various nickel titanium rotary instruments (A) Profile; (B) Protaper; (C) Hero; (D) Race; (E) Quantec; (F) K3.

In flat oval root canals, rotary file systems may be difficult to instrument the entire wall of oval canals and often fail to adequately clean and shape the canal (10). New endodontic rotary instruments of varying cross-sectional mechanical designs and tapers have been developed, targeting better cleaning and shaping ability $(11,12,13)$. The selfadjusting file (SAF) which a new concept in cleaning and shaping, was developed to overcome the inherent remaining problems of the nickel-titanium instruments (14).

The new concept and technologies continues to change the dynamics of endodontic practices in the world. Rapid and significant changes in techniques, instrument design, and the type of metals used to manufacture endodontic instruments have been 
made during the last few years in an attempt to overcome canal preparation errors (7).

This review attempts to describe factors that influence shaping outcomes with SAF file, such as instrument design, and usage parameters.

\section{The Self-Adj usting file (SAF) Design and Operation}

Self-Adjusting file (Re-Dent-Nova, Ra'anana, Israel) which hollow file designed is a novel system among the nickel-titanium files operating in a different manner (Fig. 2). It adapts itself to the canal's original anatomy and shape, longitudinally to a curved canal, as will all rotary nickel-titanium files, especially differently adapts itself to the crosssection of the canal, providing three-dimensional adaptation during the cleaning and shaping process. It is a hollow file designed as a compressible, thinwalled pointed cylinder either 1.5 or $2.0 \mathrm{~mm}$ in diameter composed of $120-\mathrm{mm}$-thick nickel-titanium lattice (Fig. 3), composed of a thin derivate of nickel-titanium lattice with high torsional and fatigue resistance (14).

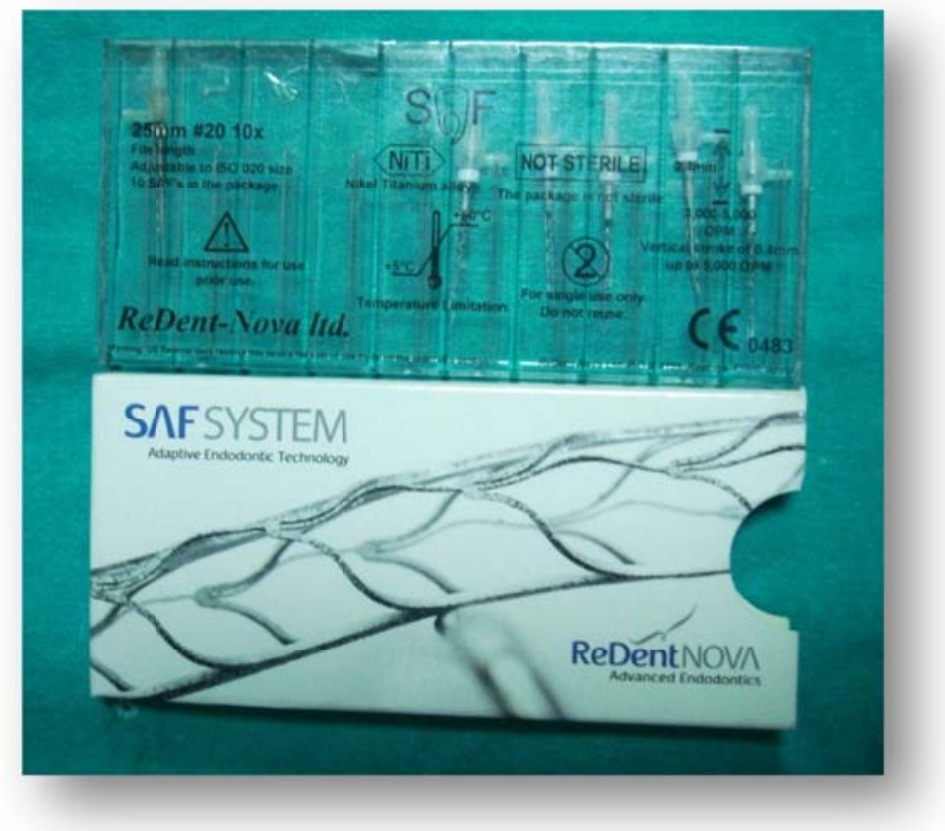

Figure 2. Self Adjusting File

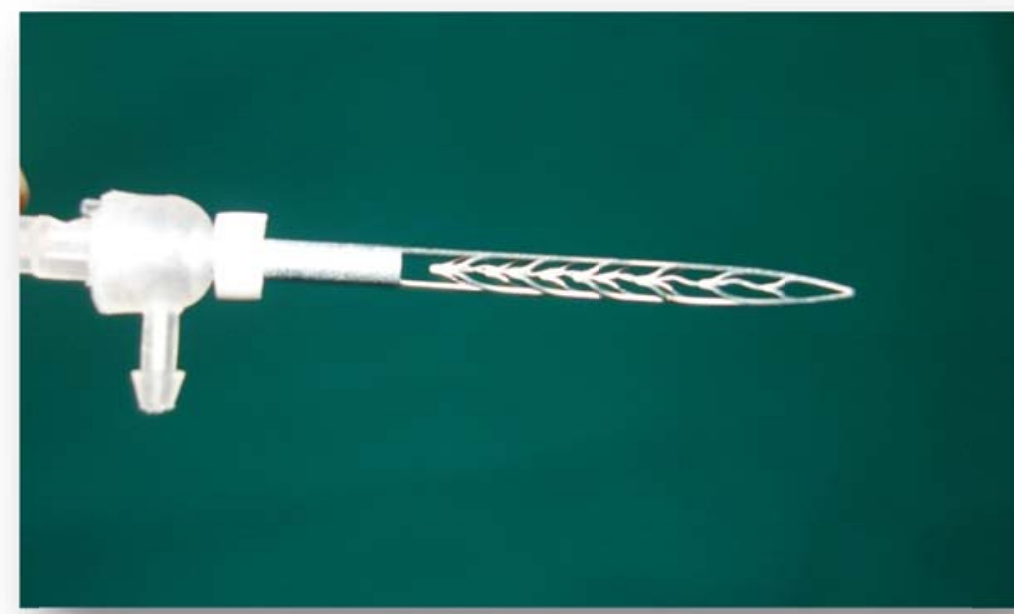

Figure 3. Hollow design of Self Adjusting File 
The $1.5-\mathrm{mm}$ and $2.0-\mathrm{mm}$ files may easily be compressed to the extent of being inserted into canal previously prepared or negotiated with respectively a \# $20 \mathrm{~K}$-file and \#30 K-file. The file will then attempt to get back its original dimensions, thus applying a continually delicate pressure on the root canal walls. In a round canal, it will get shape a round cross-section, whereas in an oval or flat canal it will get shape a flat or oval cross-section. The lattice surface is slightly abrasive and it allows removing dentin with a back-and-forth grinding motion. During its operation, SAF file is designed to be compressed while inserted into a narrow root canal. The file then attempts to regain its original dimensions, it continues to apply aperpetual delicate pressure on the root canal walls $(14,15)$.

The SAF is operated with vertical (in and out) vibrating handpieces with 3,000 to 5,000 vibrations per minute and an amplitude of $0.4 \mathrm{~mm}$ KaVo GENTLEpower dental handpiece can be used or similar combined with either a 3LDSY head (360 free rotation; Kavo, Biberach Riss Germany) (Fig. 4) or MK-Dent head (360 free rotation; MK-Dent, Bargteheide, Germany) or RDT3 head (Fig. 4) (80 $\mathrm{rpm}$ when free and stops rotating when engaging the canal walls, newly developed by Re-Dent-Nova, Ra'anana, Israel) (14).

The hollow design SAF file allows for continuous irrigation throughout the procedure. The irrigation is performed continuously during the operation used a special irrigation apparatus (VATEA Irrigation Device, ReDent-Nova). A special irrigation device (Fig. 5) is attached by a silicon tube to the irrigation hub on the shaft of the file (Fig. 6) and provides continuous irrigation flow at a low pressure and at flow rates of 1 to $10 \mathrm{~mL} / \mathrm{min}$.

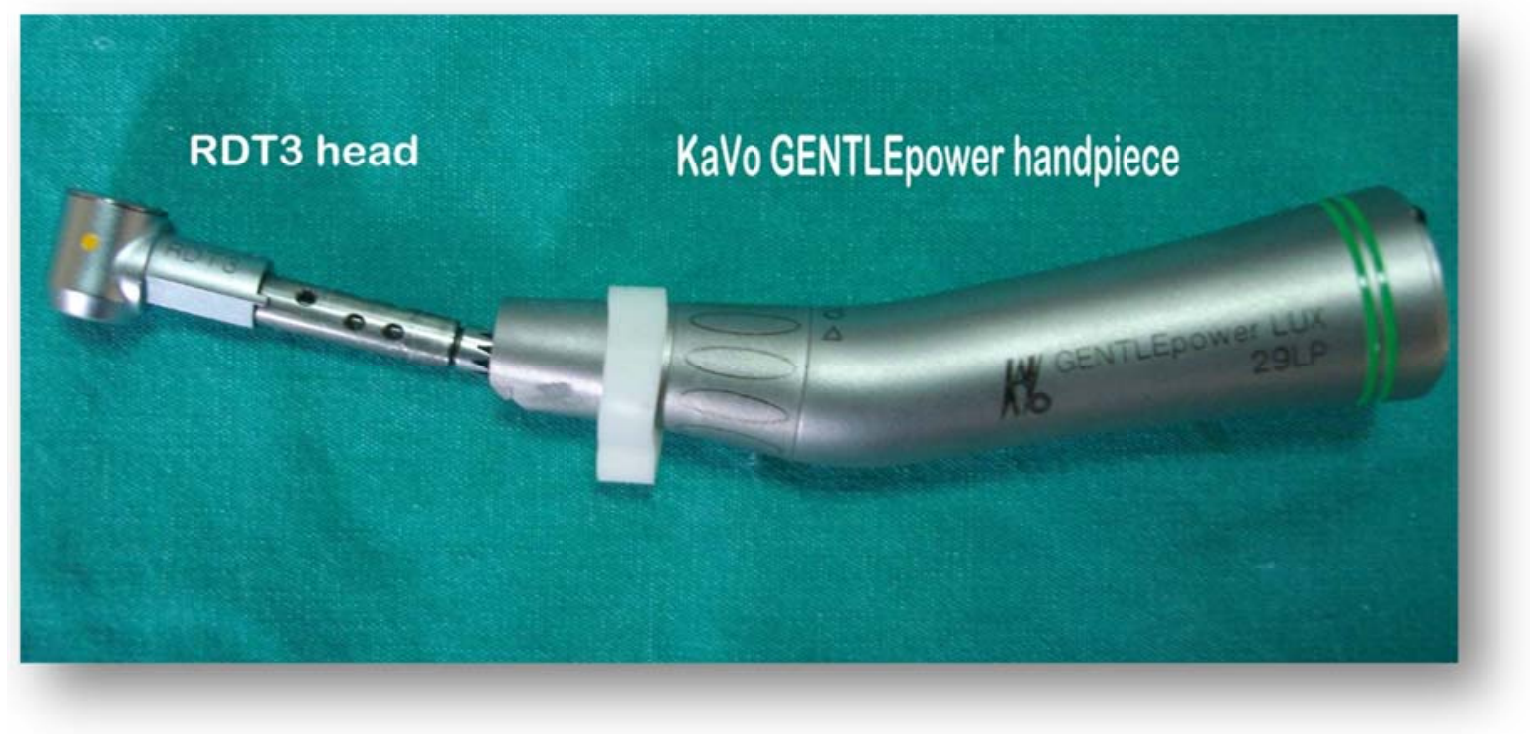

Figure 4. KaVo GENTLEpower handpiece and RDT3 head 


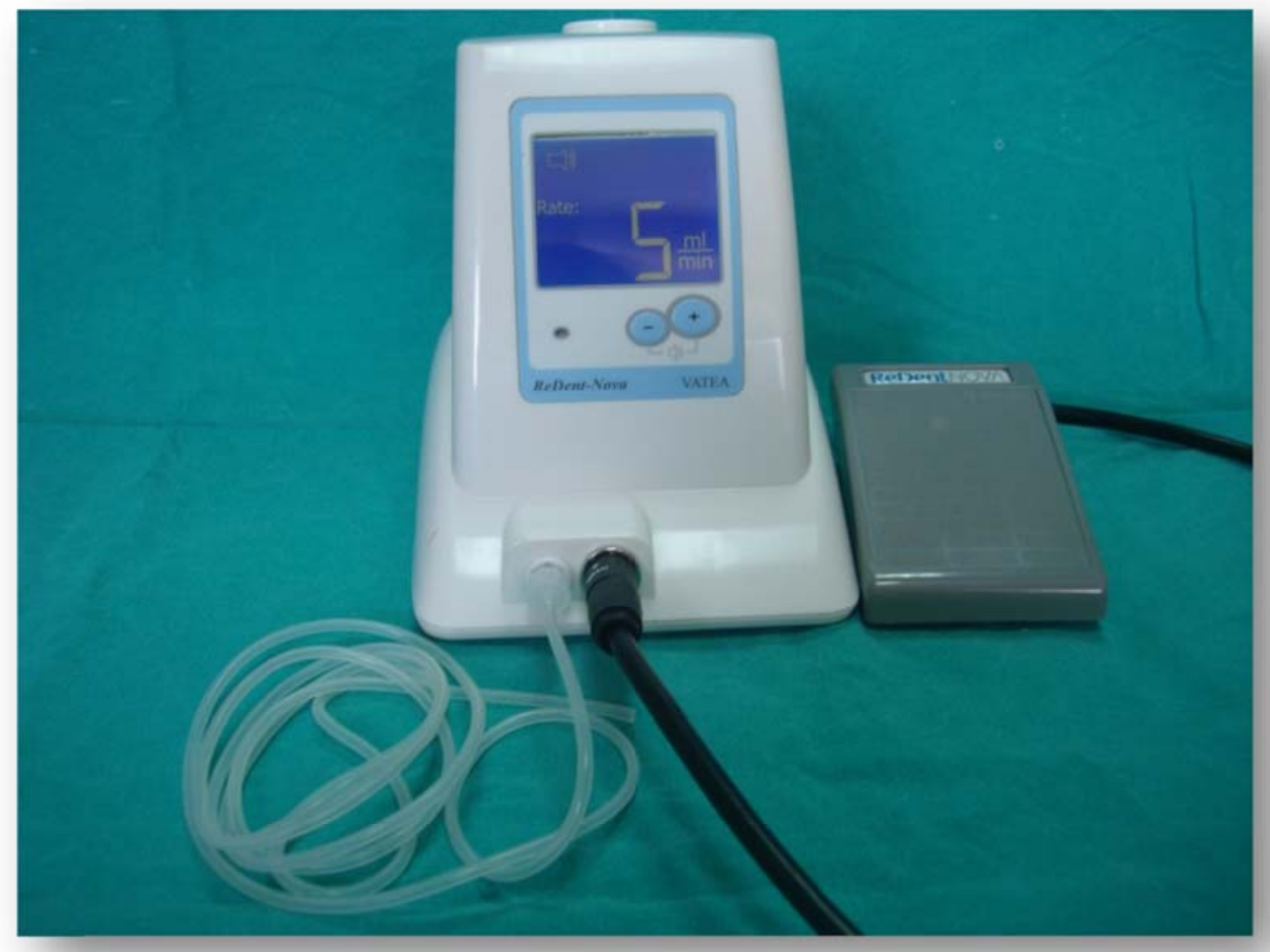

Figure 5. VATEA Irrigation Device

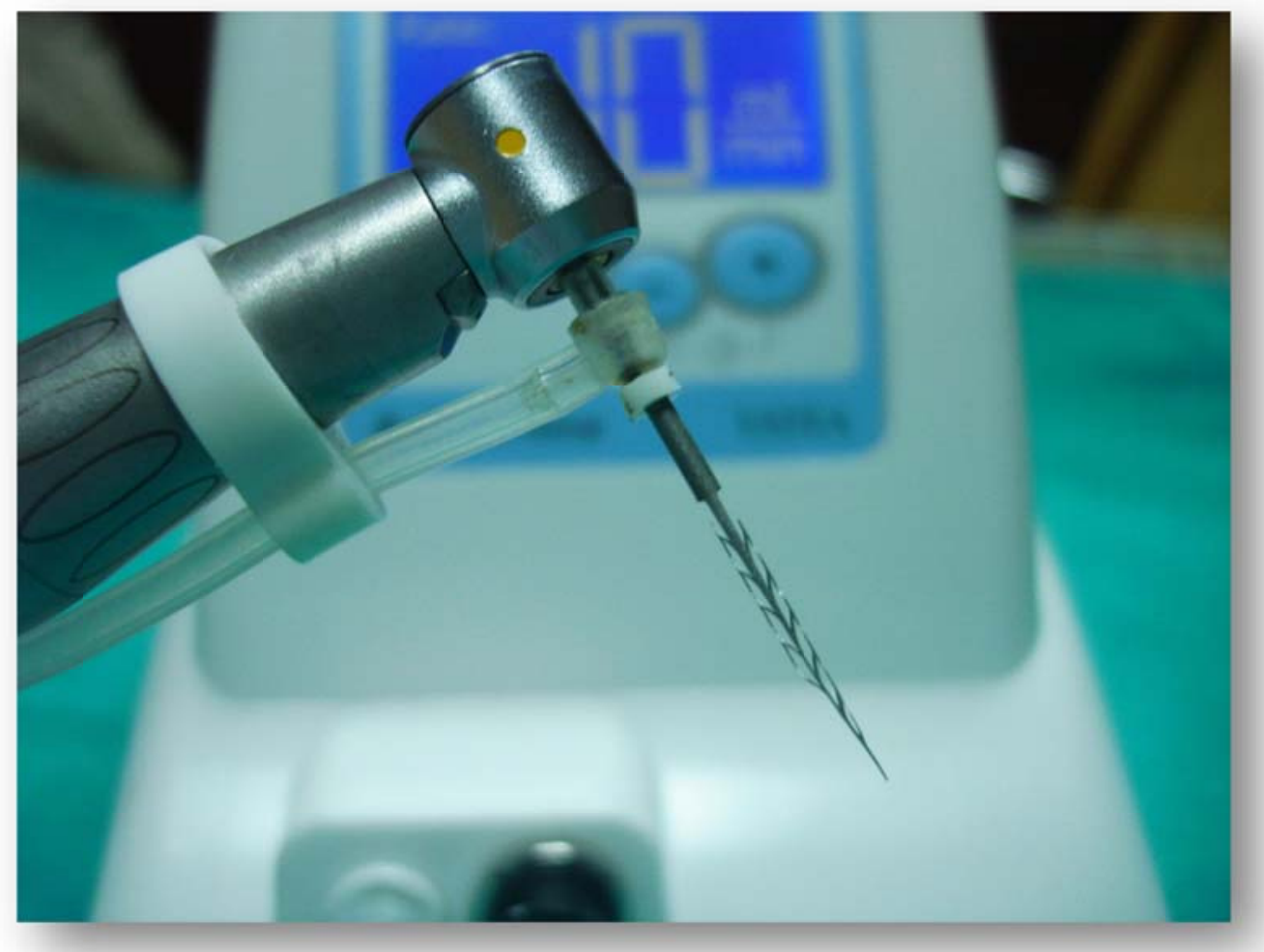

Figure 6. VATEA Irrigation Device with attached by silicon tube on the shaft of the file 
During the operating procedure, the SAF is inserted into the root canal while vibrating and is meticulously pushed in until it reaches the measured working length. The SAF file is operated in two cycles of 2 minutes each for a total of 4 minutes per canal. It is performed with in-and-out manual motion and with continuous irrigation VATEA Irrigation Device, in this way allowing continuous fresh irrigant to be present in the canal during the procedure. This procedure is reported to remove a uniform dentin layer $60-$ to $75-\mathrm{mm}$ thick from the root canal circumference. The SAF is removed from the canal for inspection after each cycle. Each SAF file is designed and recommended for single use (14).

During the first minute of each cycle of 2 minutes, sodium hypochlorite $(3 \%)$ is used as the root canal irrigant and EDTA (17\%) is used during the second minute. The flow rate of the irrigants set at $5 \mathrm{~mL} / \mathrm{min}$, resulting in a total volume of $10 \mathrm{~mL}$ of each irrigant used during the procedure with additional activation of the irrigant by its vibrating motion. After two cycles, an additional irrigation with EDTA $(17 \%)$ is used for 0.5 minutes with the vibrational mechanism turned off followed by a final short flush with sodium hypochlorite $(3 \%, 5 \mathrm{~mL})$ to remove the remaining EDTA (14).

\section{Mechanical Analysis of SAF}

Compressibility of the SAF force applied as a result of compression, surface roughness, abrasivity test, durability (torque test, ada cyclic fatigue test, free buckling fatigue test, functional fatigue-tofailure test), SAF degradation as a function of working time and irrigation experiments mechanical analysis tests were conducted as previously reported by Hof et al.(15). It can be summarized as follows (15):

a. The SAF file may be elastically compressed considerably from a diameter of $1.5 \mathrm{~mm}$ to dimensions resembling those of an ISO \# $20 \mathrm{~K}$-file because of the special design of the file.

b. The SAF file creates circumferential force when initially compressed.

c. The rough surface, combined with the force and the in-and out vibrational mechanism, allows for the removal of dentin by filing.

d. The circumferential force and the ability to remove dentin decreases as the diameter of the canal enlarges.

e. If the file is reused, the ability to remove dentin declines. f. The SAF file is mechanically durable for continuous operation for 29 minutes.

g. SAF application does not push the irrigant beyond the apical foramen.

\section{Removal of the Smear Layer in the Apical Part of the Canal}

Debridement of the root canal system is important for endodontic success (16). Irrigants must be brought into direct contact with the entire root canal wall for optimal effectiveness and it was reported that enhancement of the flushing action is essential to improve root canal cleanliness $(17,18)$. As with any endodontic instrument, the SAF produces a smear layer on the root canal walls (19). This layer should be removed in order to provide the penetration of intracanal disinfectant into the dentinal tubules and also the complete adaptation of obturation materials to the dentin walls (17). Although sodium hypochlorite has been recommended as the main irrigant, it can not dissolve inorganic dentin particles (17). Irrigation with $\mathrm{NaOCl}$ in association with a chelating agent such as ethylenediaminetetraaceticacid (EDTA) citric acid have been recommended in endodontic therapy (17). Studies have shown that debris can remain in the root canal system after instrumentation and irrigation. However, scanning electron microscopic studies show that the removal of the smear layer and debris in the apical third of the root canal using either a syringe and a needle or a chelating agent leaves much to be desired (19). It was reported that when $3 \%$ sodium hypochlorite and 17\% EDTA were used as irrigants with the SAF file, the root canal wall (including its apical third) was rendered clean of debris and the smear layer (19). It might be attributed to effective continuous substitute of the chelator in the apical third and to the mechanical vibrating action of the SAF in this region (14).

\section{Root Canal Obturation of SAF- prepared root canals}

Obturation of the root canal system has been performed using various techniques. Obturation of SAF-prepared root canals might be possible done by any of the obturation methods. Obturation using lateral compaction using chloroform-dipped customized master cones is reported. This technique has the advantage of providing visualize the shape of the SAF-treated root canals (14). Metzger et al reported that the self-adjusting files showed better 
cleaning and shaping and better adaptation of the root canal filling material (20).

\section{Clinical Use}

A series cases with SAF treatment have been completed according to protocol as described by Metzger et al (14). It was reported in more than 100 clinical cases without any file seperation (14).

\section{Conclusions}

The usage new concept of rotary nickeltitanium files adds a new quality to root canal preparation. SAF operated with continous flow of irrigation results in debris and smear free in most of the root canal walls. The SAF represents a new approach in endodontic rotary file design and operation. It contributes greatly to endodontic armamentarium. Its main features are as follows $(14,15,19)$ :

1. The SAF file is different from any nickeltitanium rotary file. It is claimed to adapt itself three-dimensionally to the shape of the root canal, including to adapt to its cross-section

2. One file is used during the procedure.

3. Canal straightening and canal transportation of curved canals are largely denied because of the lack of a rigid metal core.

4. High mechanical durability overcomes the mechanical failure of nickel-titanium instruments.

5. Hollow and flexible design allows continuous irrigation with constant refreshment of the irrigant throughout the procedure.

6. SAF file generates circumferential force.

7. It tends to keep the apical part of curved canals closer to its original location with no zipping.

8. SAF application with continuous irrigation does not push the irrigant beyond the apical foramen.

\section{References}

1. Baugh D, Wallace J. The Role of Apical Instrumentation in Root Canal Treatment: A Review of the Literature J Endod, 2005;31(5):333-340

2. Bartha T, Kalwitzki M, Löst C, Weiger R. Extended apical enlargement with hand files versus rotary NiTi files. Part II. Oral Surg Oral Med Oral Pathol Oral Radiol Endod. 2006 Nov;102(5):692-7.
3. Carvalho LA, Bonetti I, Aurelio M, Borges G. A comparison of molar root canal preparatio $\mathrm{n}$ using stainless-steel and nickel-titanium instruments. Journal of Endodontics, 1999;25(12):807-10

4. Matwychuk M, Bowles W, McClanahan S, Hodges J, Pesun I. Shaping abilities of two different engine-driven rotary nickel titanium systems or stainless steel balanced-force technique in mandibular molars. J Endod. 2007;33:868-871.

5. Walton RE, Torabinejad M. Principles and Practice of Endodontics. 2nd ed. Philadelphia, PA: Saunders; 1996.

6. Wein FS. Endodontic Therapy. 5th ed. St Louis, MO: Mosby; 1996.

7. Leif Tronstad. Clinical Endodontics, A Textbook.. 2nd ed. Thieme, New York; 2003.

8. Yoshimine $Y$, Ono $M$, Akamine $A$. The shaping effects of three nickel-titanium rotary instruments in simulated S-Shaped canals. J Endod 2005;31:373-5.

9. Hargreaves KM, Cohen S. Patways of the pulp. 6th ed. Mosby, 2006.

10. Wu M-K, Wesselink PR. A primary observation on the preparation and obturation in oval canals. Int Endod J 2001;34:137-41.

11. Yao JH, Schwartz SA, Beeson TJ. Cyclic fatigue of three types of rotary nickeltitanium files in a dynamic model. $]$ Endod 2006;32:55-7.

12. Peters OA, Paque F. Current developments in rotary root canal instrument technology and clinical use: a review. Quintessence Int. 2010 Jun;41(6):479-88. Review.

13. Ersev H, Yılmaz B, Çiftçioğlu E, Özkarslı ŞF. A comparison of the shaping effects of 5 nickel-titanium rotary instruments in simulated S-shaped canals. Oral Surg Oral Med Oral Pathol Oral Radiol Endod 2010;109:e86-e93

14. Metzger Z, Teperovich E, Zary R, Cohen R, Hof R. The self-adjusting file (Saf). Part 1: Respecting the root canal anatomy - a new concept of endodontic files and its implementation. J Endod 2010;36:679-90.

15. Hof R, Perevalov V, Eltanani M, Zary R, Metzger Z. The self-adjusting file (Saf). Part 2: mechanical analysis. J Endod 2010;36:691-96.Sdf

16. Siqueira JF Jr, Rocas IN. Clinical implications and microbiology of bacterial persistence after treatment procedures. J Endod 2008;34:1291-301.

17. Zehnder M. Root canal irrigants. J Endod 2006;32:389-98.

18. Rödig T, Döllmann $S$, Konietschke F, Drebenstedt S, Hülsmann M. Effectiveness of different irrigant agitation techniques on debris and smear layer removal in curved root canals: a scanning electron microscopy study. J Endod. 2010;36(12):1983-7.

19. Metzger Z, Teperovich E, Cohen R, et al. The Self-adjusting File (SAF). Part 3: Removal of 
Debris and Smear Layer-A Scanning Electron Microscope Study. J Endod 2010;36:697-702.

20. Metzger Z, Zary R, Cohen R, Teperovich $E$, Paqué F.The quality of root canal preparation and root canal obturation in canals treated with rotary versus selfadjusting files: a three-dimensional microcomputed tomographic study. J Endod. 2010;36(9):1569-73. 